\title{
Characteristics of hydrocarbon accumulation and exploration potential of the northern South China Sea deepwater basins
}

\author{
ZHU WeiLin ${ }^{1 *}$, ZHONG Kai $^{1}$, LI YouChuan ${ }^{2}$, XU Qiang $^{2} \&$ FANG DianYong ${ }^{1}$ \\ ${ }^{1}$ China National Offshore Oil Corporation, Beijing 100010, China; \\ ${ }^{2}$ China National Offshore Oil Corporation Research, Beijing 100027, China
}

Received July 27, 2011; accepted November 8, 2011; published online March 12, 2012

\begin{abstract}
Although the huge potential of the northern South China Sea deepwater basins has been proven by a series of discoveries that followed the exploration breakthrough of well LW 3-1-1, recent drilling and other studies have demonstrated the uniqueness and complicated nature of hydrocarbon accumulations of the deepwater basins there. Based on a review of previous work and the latest exploration activities and studies, the purpose of this paper is to discuss the critical controls for hydrocarbon accumulations in the deepwater basins of the northern South China Sea. A terrestrial-marine transitional coal-bearing source rock is proposed to be the primary source rock for the deepwater basins. A marine source rock, which was first identified as contributing to hydrocarbon generation in this region, probably plays a significant role in the deep- and ultra-deep water basins south to the Pearl River Mouth and Qingdongnan basins. The shelf margin delta depositional systems in the Baiyun Sag, sourced from the Pearl River, are currently primary exploration targets in the deepwater part of the Pearl River Mouth Basin, whereas the western Red River deltaic-submarine fan depositional systems, initially proven by drilling, are the possible major exploration reservoirs in the Qingdongnan deepwater areas. Current deepwater exploration targets at the large-sized structural traps and deep and ultra-deep areas in the south of the Pearl River Mouth and Qingdongnan basins will be the future exploration focus. Deepwater exploration activities and relevant fundamental studies, supporting and promoting each other, are of great importance to the national energy supply of China, the basic regional studies of the South China Sea, advancements in technology, and development of related deepwater industries, and will safeguard national sovereignty and territorial integrity.
\end{abstract}

northern South China Sea, deepwater exploration, hydrocarbon accumulation

Citation: Zhu W L, Zhong K, Li Y C, et al. Characteristics of hydrocarbon accumulation and exploration potential of the northern South China Sea deepwater basins. Chin Sci Bull, 2012, 57: 3121-3129, doi: 10.1007/s11434-011-4940-y

Petroleum exploration activities in deepwater and ultra-deep water environments are becoming increasingly important, with significant discoveries adding to global reserves since the 1990s. To date, the passive continental basins of the Atlantic, and particularly the Gulf of Mexico basin, have dominated global deepwater exploration efforts. Recently however, in the wake of a series of commercial discoveries starting with well LW 3-1-1, the northern South China Sea (SCS) deepwater basins have become a new focus for deepwater exploration.

However, disparities have emerged in the SCS and other

*Corresponding author (email: zhuwl@ cnooc.com.cn) passive deepwater basins with regard to regional tectonic settings and structural attributes, which have led to variations in basin formation and evolution and the controls on hydrocarbon generation, migration and accumulation [1]. In addition, a thorough understanding of the petroleum geology of deepwater basins is critical during the initial exploration stage because of the high commercial threshold and geological risks. Therefore, in the unique geologic setting of the deepwater SCS, an analysis of the major controls on hydrocarbon accumulation is of great importance to deepwater exploration.

Based on a summary of recent exploration practices, the work presented here: (1) attempts to analyze the hydrocar- 
bon accumulation conditions of the northern SCS deepwater basins, (2) introduces the source rocks, resource potential, depositional systems and reservoir characteristics of the basin, and (3) provides suggestions for future studies and exploration.

\section{Exploration history of the South China Sea deepwater}

Previous exploration activities and relevant studies in the northern SCS deepwater provide a basis for present and future deepwater exploration and studies of key aspects of hydrocarbon accumulation in the area. Currently, China's deepwater exploration is mainly being undertaken in the slope areas of the Pearl River Mouth Basin (PRMB) and Qingdongnan Basin, extending over an area of $120000 \mathrm{~km}^{2}$ in water depths of 300-3200 m.

As early as the 1930s to 1950s, based on onshore surveys and regional studies of East Asian geology, Chinese geologists proposed that the South China Sea had Cenozoic sedimentary basins with hydrocarbon potential. Since the 1960s regional exploitation has been carried out by various governmental ministries. During this period, many gravity and magnetic data sets have been acquired and numerous wells have been drilled; the PRMB and Yinggehe Cenozoic sedimentary basins were recognized and proven, with thickest deposits exceeding $10 \mathrm{~km}$. Drilling efforts recovered hydrocarbons that initially suggested significant resource potential; however, no fields were identified because of backward technologies and a lack of geological understanding [2].

A full investigation carried out by China National Offshore Oil Corporation (CNOOC) in early 1980s drew attention to the huge hydrocarbon potential of the South China Sea, indicating resources of about 3.2 billion tons in the Baiyun Sag (accounting for 52\% of the PRMB). Exploration blocks were opened for bidding in the SCS, leading to foreign oil companies acquiring several tens of thousands of kilometers of 2D seismic from 1983 to 1996 and the drilling of 14 wells along the northern shallow margin of the Baiyun Sag. Among them, well BY 7-1-1 was drilled by Occidental Oil Company in 1987 in a water depth of $500 \mathrm{~m}$, close to a world record at that time. However, those activities only discovered one oil field, the LH 11-1 reef oil field. Soon after, foreign companies retreated from the SCS and exploration efforts in the region slowed down. However, CNOOC's researchers, with the benefit of financial and technological experience gained from foreign counterparts - particularly in comparison with the nearby shelf — persisted in petroleum geological studies and investigations of the potential of the deepwater basins.

At the beginning of the 21st century, a total of 16 wells were drilled successfully on the north slope of the Baiyun Sag to test the deepwater hydrocarbon potential. This led to the discovery of the Panyu gas field group and further demonstrated the exploration potential of the Baiyun Sag. The success again attracted the attention of foreign oil companies, which has led to a resurgence in cooperative deepwater exploration. Meanwhile, CNOOC has dramatically increased investment in self-operated explorations and studies, and greatly promoted deepwater exploration.

In the wake of the success of LW 3-1-1 in June 2006, symbolizing the start of a new deepwater exploration era, LH 34-2 and LH 29-1 made further discoveries, followed by the LS 22-1 gas discovery in the Qingdongnan Basin by the end of 2010. These successes correspond to an overall breakthrough in deepwater exploration in the PRMB and Qingdongnan Basin. However, the complexity of hydrocarbon accumulations in deepwater settings has also been proven by failures in exploration drilling.

Based on deepwater investigations to date, four critical factors have been identified for successful exploration in deepwater settings: (1) deepwater basin ( $\mathrm{sag}$ ) size, (2) source rock quantities and resource potential, (3) reservoir distribution, and (4) exploration direction and prospect optimization. These four factors will be the focus of future deepwater exploration and study.

\section{Cenozoic shelf (shallow-water) and slope (deepwater) basins in the northern SCS}

Unlike the typical Atlantic passive continental margin, the relatively small scale northern SCS continental margin developed in a marginal sea. It has experienced a transition from a Mesozoic active continental margin to a Cenozoic passive margin. The unique structural attributes and basin formation history of the SCS is the result of multiple tectonic superpositions [1,3-5]. The superpositions are the result of: (1) the back-arc spreading caused by the Pacific Plate subducting under the Eurasian plate, (2) South China Sea spreading, (3) the Red River strike-slip fault system caused by the remote effect of the collision between the Indian and Tibetan plates, and (4) the oblique strike of the collision between the Philippine and Indian plates. Since the Cenozoic, the northern SCS has experienced multiple rift stages, and formed a series of basins from the shelf (shallow water) to slope (deepwater) (Figure 1).

The northern SCS shallow shelf basins are currently primary exploration areas for CNOOC and by the end of 2010, a total of 75 oil and gas fields with over $1.05 \times 10^{9} \mathrm{~m}^{3}$ of oil and $350 \times 10^{9} \mathrm{~m}^{3}$ of gas have been discovered. To date, 257 $\times 10^{6} \mathrm{~m}^{3}$ of oil and $67.3 \times 10^{9} \mathrm{~m}^{3}$ of gas have been produced.

Because of the frontier nature of deepwater exploration areas, it is critical to analyze whether the petroleum geological settings are similar to those in shallow water. Analysis of analogs indicates that the deepwater has Cenozoic sedimentary basins are similar to those found in shallower water. 


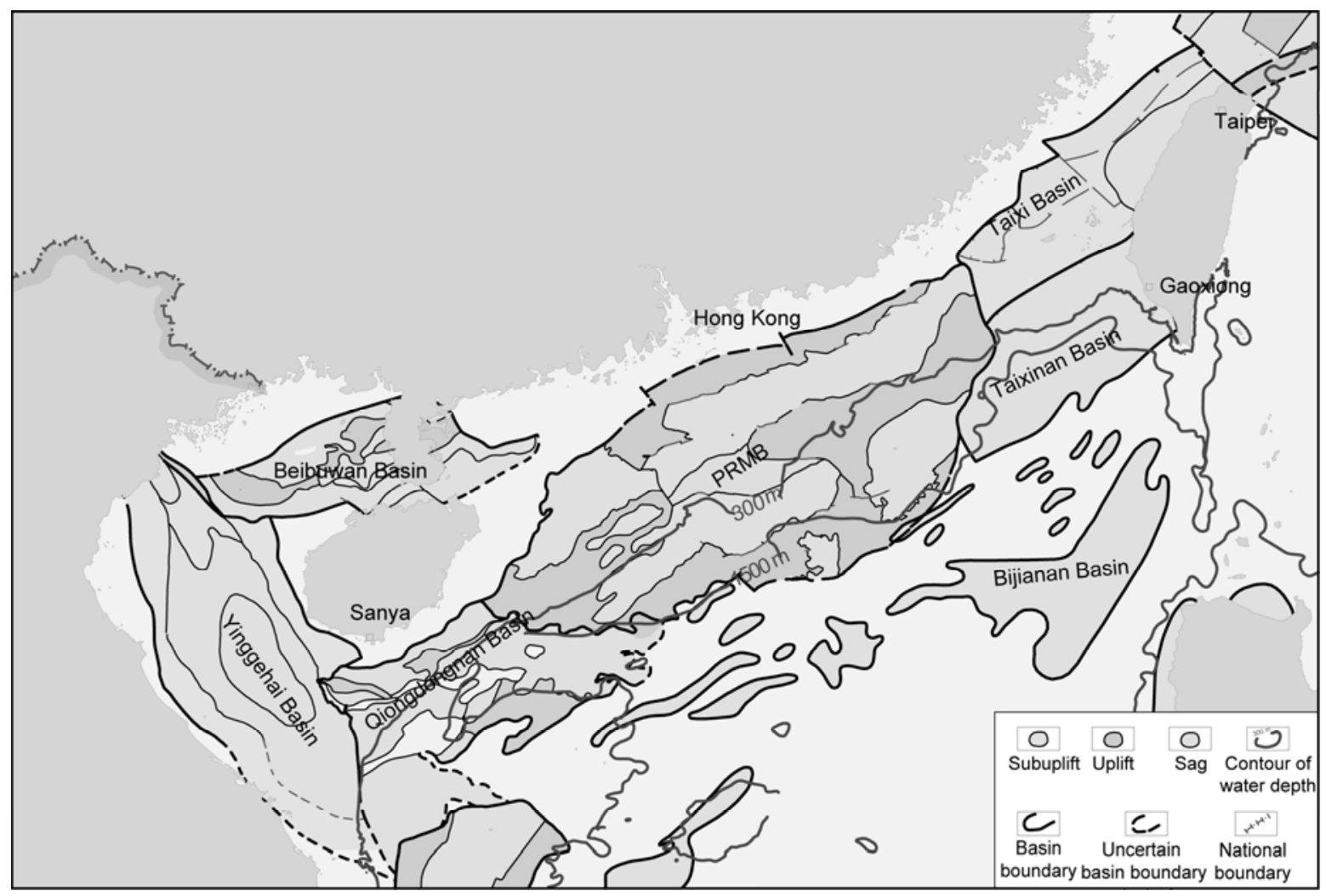

Figure 1 Distribution of continental margin sedimentary basins of the northern SCS.

The northern continental margin experienced three tectonic stages: Paleogene three phase rifts, Neogene thermal subsidence and Neotectonics. The deepwater basins, similar to their shallow-water counterparts, correspondingly contain three sets of deposits: (1) terrestrial-marine transitional strata from the rifting stage, (2) Paleocene-Eocene, lower Oligocene, middle-upper Oligocene and the Neogene post-rift marine depositions, and (3) Neotectonics strata [6] (Figure 2). A number of deepwater sags: Baiyun, Ledong- Lingshui, Songnan-Baodao, and Changchang, are identified by seismic profiles, with maximum Cenozoic deposition ranging from 8000 to $>10000 \mathrm{~m}$, a huge resource potential [7].

Although the deepwater Cenozoic basins are similar to those in shallow water, the differences in the lithospheric thermal structure and basin deformation can be seen clearly to have resulted from the thinning of the lithosphere (including the crust) from the shelf to the slope. Differences are influenced significantly by the formation and evolution of the deepwater basins. Moreover, the northern SCS has experienced multiple stages of regional tectonic movement since the Cenozoic (particularly in the formation and evolution of the SCS). This, together with the possible lithospheric transverse structural heterogeneity, caused by previous structures, and led to a difference in distributed stress and deformation in various parts of the structure. This further caused variations between shallow-water and deep- water basins, different slope deepwater basins, and even different sags in one basin.

The influence of the regional tectonics of the northern SCS-especially the formation and evolution of marginal basins-as well as the tectonic sequence and deposition filling styles in the area, play significant roles in the analysis of critical questions associated with deepwater basin formation, hydrocarbon generation and accumulation.

\section{Hydrocarbon potential resulting from three sets of source rocks in the deepwater basins}

Three set of source rocks have been identified from the deepwater basins in the northern SCS: (1) Eocene lacustrine source rocks that developed in the primary rifting stage, (2) Oligocene terrestrial-marine transitional source rock that developed during a late rifting stage, and (3) Miocene marine source rock that developed in a depression stage [6]. The Eocene lacustrine source rocks (e.g. the Liushagang Formation in the Beibuwan Basin and the Wenchang deep lacustrine source rock in the PRMB) are the primary oil source rocks for the shelfal basins. The transitional coal-bearing source rocks are the major source for gas, as represented by the Enping and Yacheng formations in the PRMB and Qingdongnan Basins respectively. Miocene marine source rock so far has only been discovered in the 


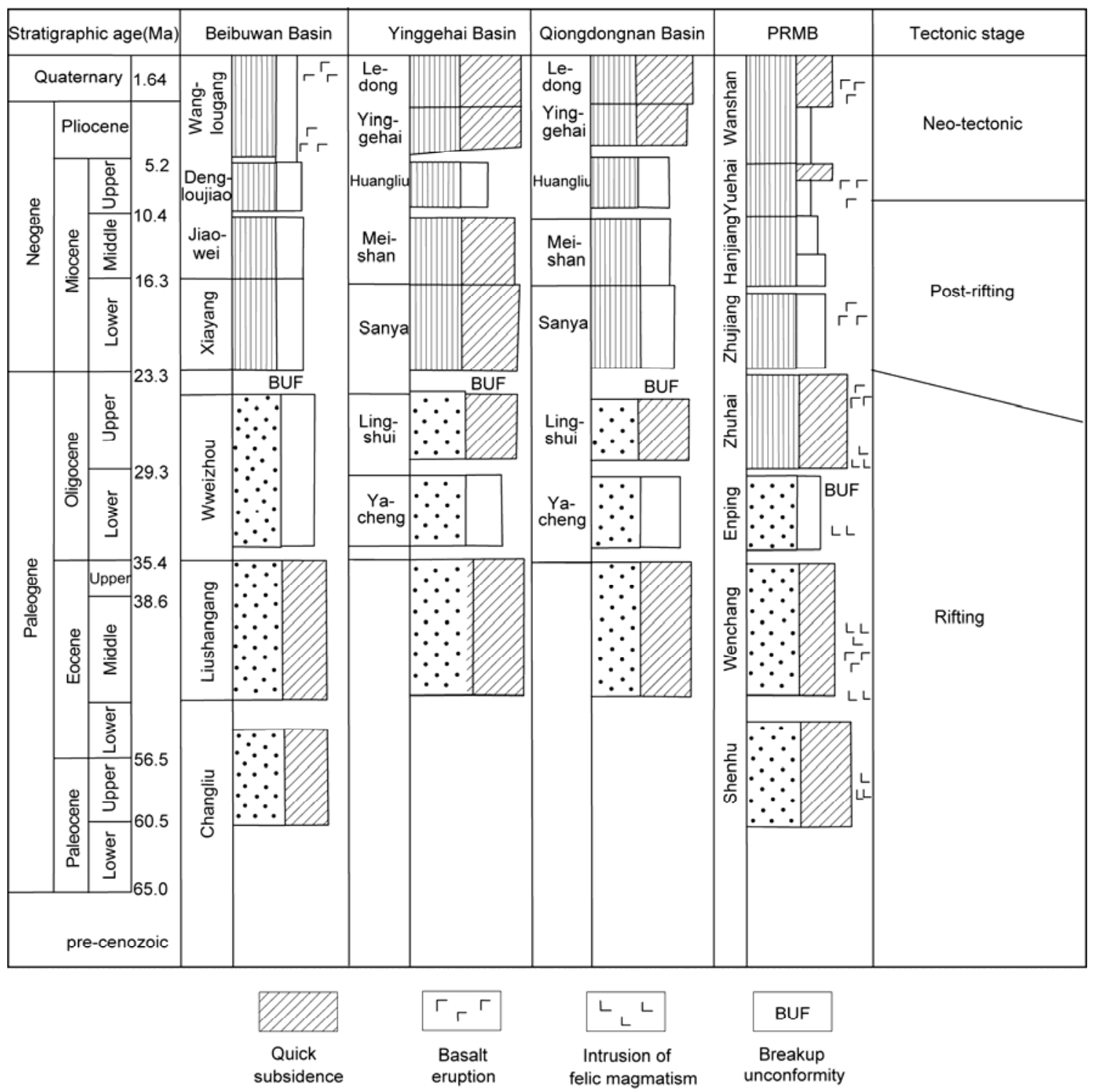

Figure 2 Major tectonic evolution stages and strata of northern SCS continental basins [6].

Yinggehai Basin where it is the primary source rock [6]. The deepwater basins, have a similar history to that of the shelf. The same three sets of source rocks have also developed there.

However, further study is particularly necessary on the source rocks of deepwater basins because of the differences in the mechanisms of hydrocarbon generation between shelf and deepwater basins. These differences are associated with the decreased heat flow and geothermal gradient in deepwater settings because of the thinning of the shelf-slope lithosphere and crust in the northern SCS $[1,7,8]$. Recent hydrocarbon source analyses for the deepwater suggest that the transitional source rock is the most important, but also demonstrate the contribution of the marine source rocks.

\subsection{Terrestrial-marine transitional formations: primary source rock for deepwater basins}

Deepwater drilling attributes the transitional source rocks, including the Enping and Yacheng coal-bearing formations in the PRMB and Qingdongnan Basin, to be the primary source rocks. These formations comprise coal, carbargilite and grey mudstone and formed during the shrinkage of a dominantly lacustrine basin with intermittent marine transgressions. The source rocks developed widely and stably.

Geochemical analysis indicates that the transitional source rocks, with a relatively high organic content (Table 1), are mainly sourced from terrestrial high plants. The kerogen is mainly comprised of coal and exinite, with a great potential for gas and in its early stage for liquids as well. 
The gas discovered in the deepwater Baiyun Sag, is sourced from coal, and has high levels of benzene and toluol. These correlate well with the Enping source rock (Figure 3), which indicates that the gas is mainly sourced from Enping transitional source rock. Abundant bicadinanes (W, T), the proxy of high plant resin, are detected in oil from the Baiyun Sag, indicating that significant hydrocarbons originate from the transitional source rock [9].

\subsection{The discovery of marine source rocks expands area of deepwater prospectivity}

Abundant bicadinane and oleanane have been detected in the oil from the LW 3-1, LH 34-2 and LH 29-1 fields of the Baiyun Sag. The Enping terrestrial-marine transitional source rock has abundant bicadinane, and the Zhuhai and Zhujiang formations have a lot of oleanane; both bicadinane and oleanane are proxies of terrestrial high plants. The good correlation in the oeanane content between the Zhuhai Formation source rock and oil sample suggests that the hydrocarbons of the Baiyun Sag come from the Enping transitional source rock and the Zhuhai marine source rock. The contribution of marine source rock is further confirmed by the $\mathrm{C}_{30}$ sterane detected in oil samples from the Baiyun Sag.

Oligocene and Miocene marine shales have been penetrated by many wells in the northern SCS deepwater. Analysis suggests that the organic matter from the shale is primarily found in vitrinite, inertinite and exinite sourced from terrestrial high plants. Dinoflagellata, algae and an amorphous mass are also detected, but in small quantities. The kerogen types are of II 2 and III.

There is a higher total organic content (TOC) found in the Zhuhai Formation marine source rock than that of the Zhujiang Formation (Figure 4). For the latter, the relatively high contents are found only in shelf wells XJ 33-2-1 and PY 15-1-1, and on the deepwater slope. TOC is very low, about $0.44 \%$ in well LW 3-1-1, which changes the classification of the Zhujiang marine source rock into a poor non-source rock. The Zhuhai marine shale, with an average TOC of $1.08 \%$, is a fair source rock. A hydrocarbon generation kinetics simulation demonstrates that in well LW 3-1-1, the Zhuhai marine source rock has huge hydrocarbon potential. The cumulative hydrocarbon yields up to $450 \mathrm{mg} \mathrm{HC/g}$ TOC and the generation of more liquid in the early stage.

Gravity and magnetic analysis highlights a series of basins and sags developed in the deep- to ultra-deep-water south to the PRMB and Qingdongnan Basin, but with a rel- atively small size and thin deposition. The marine source rock, widely and stably distributed in these basins and sags, possibly generates hydrocarbon as the geothermal gradient increases in the deep- to ultra-deep-water areas. Therefore, a re-evaluation of the exploration potential of the deep- to ultra-deep water basins and sags is needed, so that future exploration can expand into these areas.

\subsection{Eocene lacustrine units: potential as source rocks}

In the Eocene, the northern SCS continental margin was warm and humid, and plants thrived in a lacustrine environment; the weather was favorable for phytoplankton resulting in regular blooms. In general, organic matter was preserved and accumulated in the large and deep lakes, which were highly productive [11]. The Eocene moderate-deep lacustrine source rock has been proven as the primary oil source rock in the shelf basins. The planktonic algae of the interval $3190-3240 \mathrm{~m}$ in well LW X-1-1 is dominated by a microflora assemblage. Fluvial and lacustrine algae, with a content up to $90.7 \%$, dominated by Pediastrum, followed by Granodiscus and Leiosphaeridia, Botryococcus braunii and hystrichosphere are odd. The Paleogene interval is rich in algae and assumed to have formed in a freshwater lacustrine environment with a well defined salinity. During deposition of this interval, the lake water was highly productive and the planktonic algae thrived.

Basin modeling demonstrates that the Eocene source rocks are a potential source rock for deepwater plays. Beneath the slope, high geothermal conditions caused the major source rock to be more rapidly matured or over-matured.

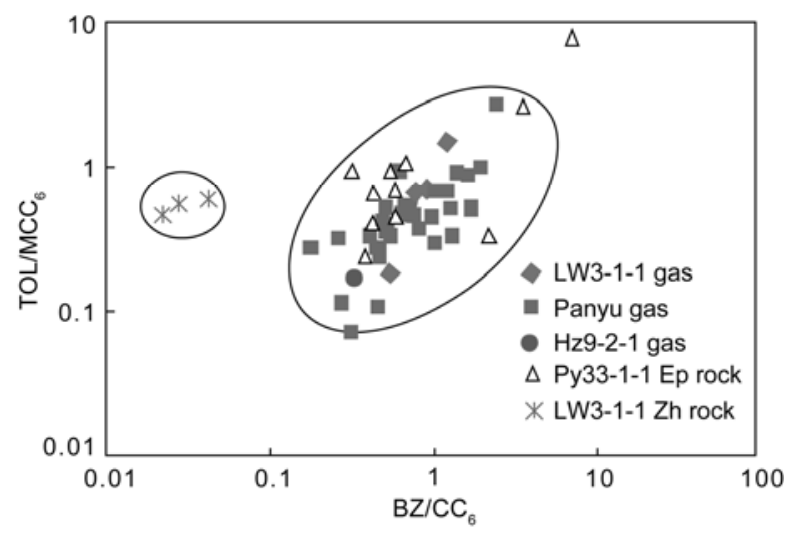

Figure 3 Relationship between gas and contents of benzene and toluol in PRMB.

Table 1 Organic content of source rocks in the northern SCS deepwater basins

\begin{tabular}{|c|c|c|c|c|c|c|c|}
\hline Basins/Sag & Source rock & Sedimentary facies & TOC (\%) & $\mathrm{S} 1+\mathrm{S} 2(\mathrm{mg} / \mathrm{g})$ & Chloroform bitumen A (\%) & $\mathrm{HC}(\mathrm{ppm})$ & Organic type \\
\hline \multirow{2}{*}{ Qingdongnan } & Lingshui & marine & 0.568 & 1.641 & 0.0793 & 508 & II2-III \\
\hline & Yacheng & transitional & 0.818 & 1.531 & 0.155 & 1628 & II2-III \\
\hline \multirow[t]{2}{*}{ Baiyun } & Zhuhai & marine & 0.67 & 0.49 & 0.046 & 160 & II2-III \\
\hline & Enping & transitional & 2.19 & 2.30 & 0.096 & 804 & II2-III \\
\hline
\end{tabular}



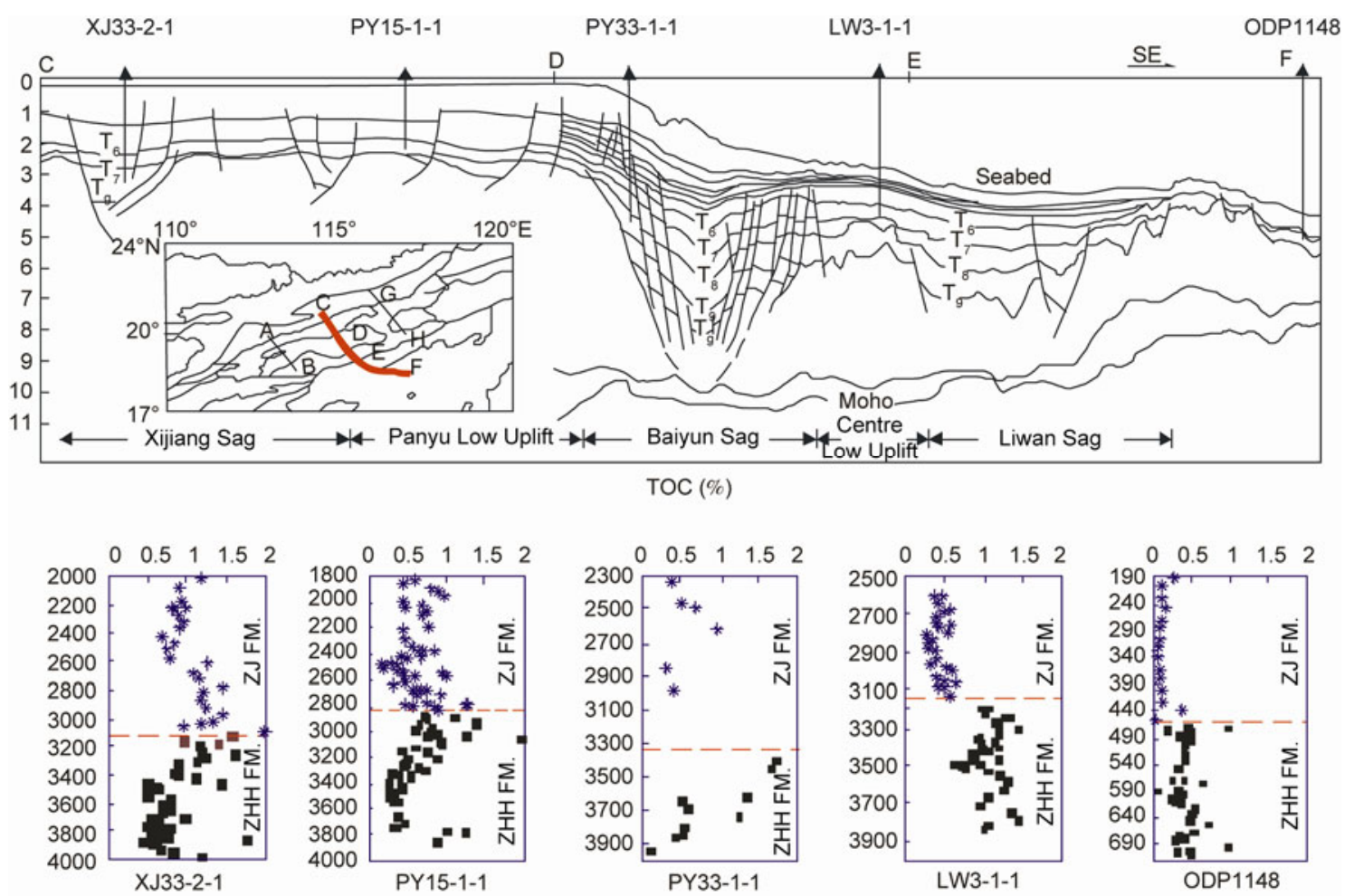

Figure 4 Organic content from shallow to deepwater for the Zhuhai and Zhujiang Formations, PRMB [10].

Hydrocarbon generation and expulsion started very early and might have ended up being dominated by cracking gas.

\subsection{Distribution of the three possible source rocks}

The three set of source rocks are distributed in zones (Figure 5). In the PRMB, the Eocene Wenchang Formation lacustrine source rock mainly contributed to the shallow shelf Zhu I depression, with the Enping transitional coal-bearing source rock playing a key role in the deepwater slope Zhu II depression. The marine source rock is a possible primary source rock for the deep- to ultra-deep water areas south to the PRMB. Therefore, an understanding of the type and distribution of source rocks is important for deepwater exploration.

\section{Long-term sediment supply from the Pearl and Red rivers to deepwater areas}

Most global deepwater discoveries have been found in turbidity submarine fan depositional systems. However, the absence of large-scale rivers in the northern SCS has resulted in the development of only small-scale deltaic depositional systems and turbidity systems. Furthermore, sediments sourced from southern China travel through areas of shallow depression before being deposited on deepwater slopes, and therefore have distinctive distal-source characteristics. Such deepwater deposition and the resulting res- ervoir rocks have features that are different from those of the typical Atlantic passive margin basins. As a result, the definition and characterization of good reservoir units are critical for deepwater exploration in the northern SCS.

Studies reveal that the Pearl and Red rivers have been long-term primary sources of sediment for the depositional system in the northern SCS [5,6,12-14]. The Oligocene-Miocene shelf-margin deltaic depositional systems of the Baiyun Sag in the PRMB, sourced by the paleo-Pearl River, are the current deepwater exploration targets. In the Qingdongnan deepwater basin, recent drilling has identified, for the first time, central channel sandstones sourced from the Red River [7-14].

\subsection{Shelf margin deltaic deposition in the Baiyun Sag}

Integrated analyses of wells and 3D seismic data demonstrate that an Oligocene-Miocene shelf-margin delta depositional system developed in the Baiyun Sag (Figure 6). In the Oligocene, the shelf margin delta was dominated by delta front sediments and developed down to the slope following an "S" shape, as influenced by the shelf break. In the Miocene, the depositional features changed from the outer shelf to upper slope. The shelf-margin delta front systems deposited as: (1) delta fronts (distributary channels and sand bars) to the shelf-slope valley channels, (2) delta front slump gravity tongues (slope fans), and (3) occidental carbonates from the Dongsha uplift. The deposition was controlled by the shelf-margin delta and shelf break and developed a 


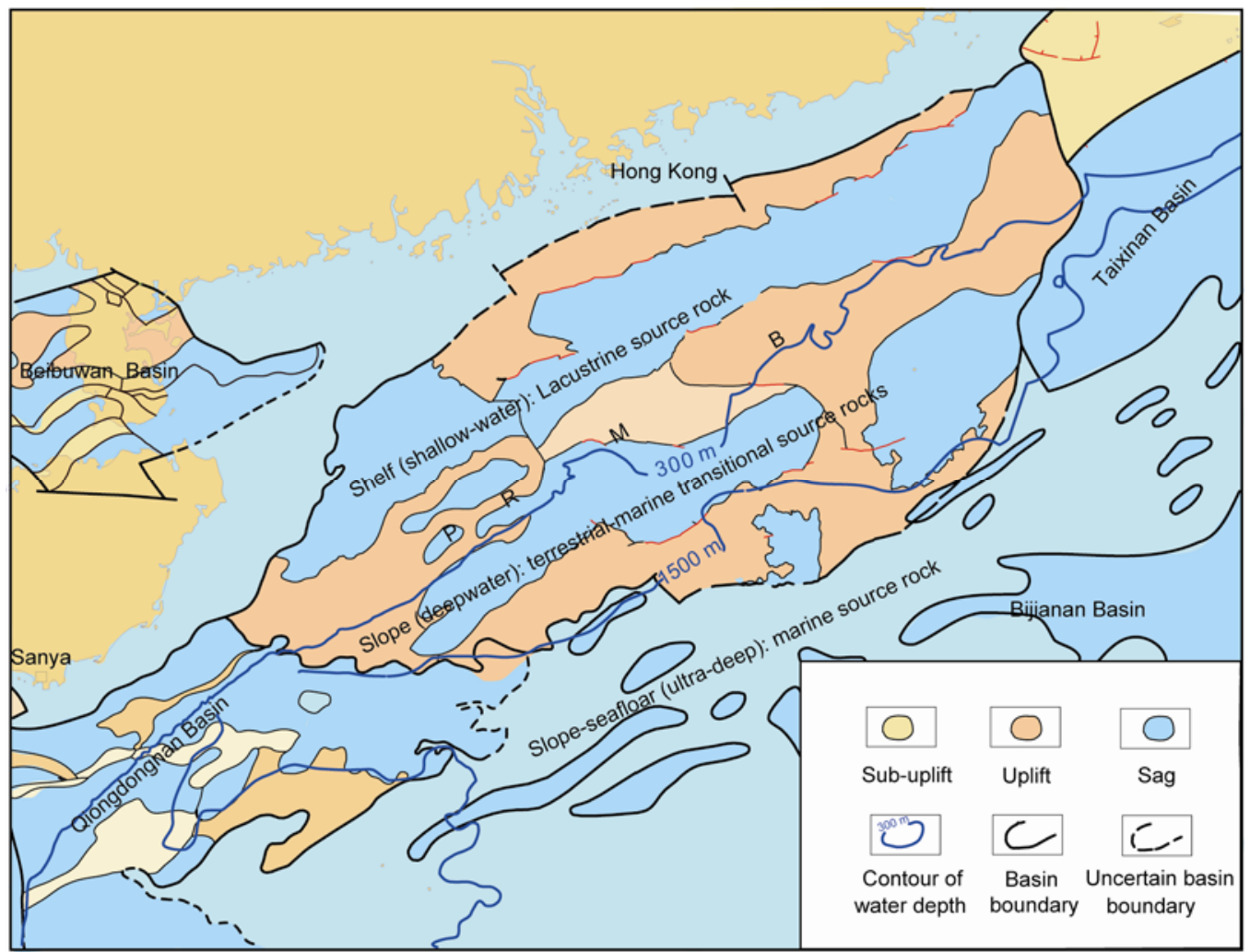

Figure 5 Zonal distributions of the source rocks in the northern SCS.

shelf-marginal delta system and good deepwater reservoir units (Figure 6).

Recently, the discoveries LH 34-2 and LH 29-1 in the Baiyun Sag deepwater further confirmed the relationship between shelf-margin delta systems and the distribution of good deepwater reservoir units. This further indicates the importance of deposition systems to hydrocarbon exploration.

\subsection{Red River delta-submarine fan systems in Yinggehai-Qingdongnan Basins}

The Red River, another important river developed in the northern SCS, provides significant sediments that are deposited in the Yinggehai Basin, in the northwestern SCS [5, 6]. Analysis of seismic and well data from the YinggehaiQingdongnan basins has led to the recognition of a largescale NW-SE oriented submarine fan, developed in middle-late Miocene (Huangliu Stage) and sourced from the Red River [14]. Wang et al. [14] proposed that the submarine fan reached its maximum extent in the late Miocene (10.5-5.5 Ma, Huangliu Stage), with an area $>10000 \mathrm{~km}^{2}$ and a maximum thickness of about $2000 \mathrm{~m}$. Further sedimentary facies analysis indicates that the sediments of the submarine fan were mainly provided by the Red River, together with the Red River delta and relevant marine valleys formed by the Red River depositional system. Since the Pliocene, the submarine fan has shifted into central channels, several hundred km long in the Qingdongnan Basin.
Drilling over many years has not resulted in any commercial discoveries along the slope break of the Qingdongnan Basin; a shortage of reservoir material is a possible reason for this. By 2010, the drilling of structure LS 22-1, aimed at the central channel of the system, found nearly 60 $\mathrm{m}$ of gas with good reservoir conditions. An analysis of the source of sediment will provide a new means of predicting and studying of the Qingdongnan deepwater reservoir.

Analysis of the depositional systems and reservoirs of the northern SCS deepwater should not limit current exploration targets. Future investigations will consider the influence and controlling effects during deepwater basin evolution that come from significant specific events that occurred in relation to the SCS, Tibetan Plateau uplift, Taiwan Mountain Range uplift, and SCS spreading.

Furthermore, analog analysis indicates that the northern part of the SCS has similar conditions for carbonate deposition when compared to the central-southern SCS and neighboring shelf where large-sized carbonate pools have been discovered; therefore, we suggest that carbonate reservoirs will be the future focus in deepwater exploration.

\section{Characteristics of hydrocarbon accumulation and future directions in exploration}

Hydrocarbon accumulations are possible throughout the 


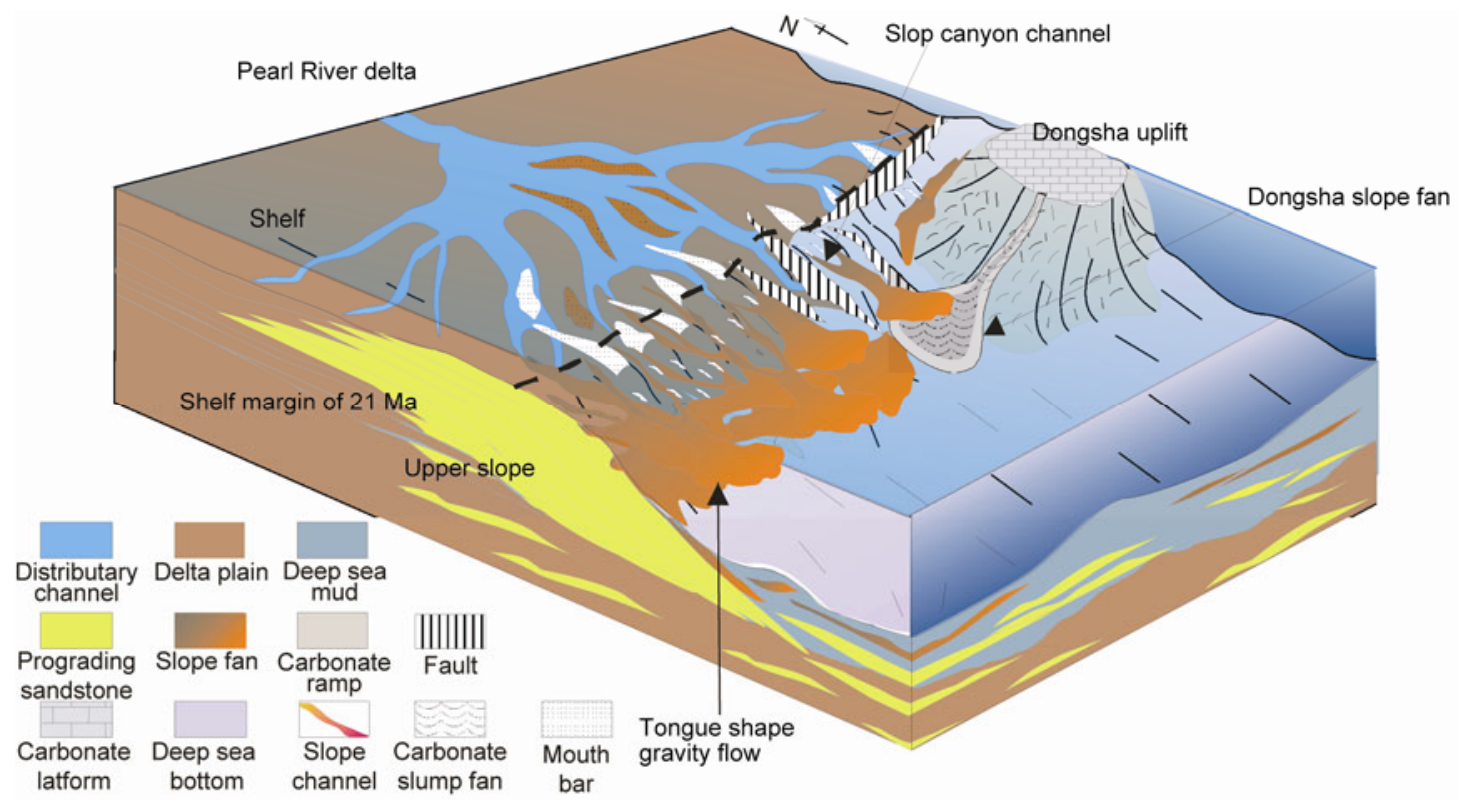

Figure 6 Shelf-margin delta deposition system in the Baiyun Sag, PRMB.

series of Cenozoic deepwater basins and sags in the northern South China Sea. In addition to the large Baiyun, Ledong-Lingshui, Songnan-Baodao and Changchang Sags in the PRMB and Qingdongnan Basin are several smaller basins and sags in the deep- and ultra-deep water in the southern parts of the PRMB and Qingdongnan Basin.

The three sets of source rocks in the deepwater regions of the northern SCS potentially contribute to the generation of hydrocarbons. Of these, the transitional source rock is the primary source rock producing II2-III type Kerogen, and resulting mainly in the generation of gas under the high geothermal gradient of the slope basins. Simulations indicate that hydrocarbon distribution is primarily controlled by the thermal evolution of the source rocks. For example, the source rock in the Qiongdongnan Basin is matureovermature and mainly generated gas, whereas in the PRMB, the source rock is mature-highly mature and mainly generated gas and oil. In the Baiyun Sag, the source rock of the margin is mainly in the oil generation window because its thermal evolution is weaker than in the center of the basin, where it is in the gas generation stage. In the smaller deep- to ultra-deep-water basins, hydrocarbon generation is possible under later high heat flow conditions.

Benefiting from the long-term supply of sediments from Pearl and Red rivers, shallow deltas, submarine fans and carbonate reefs have developed in the northern SCS. To date, more than 50 large- to medium-sized structural traps and over 30 reefs have been identified in the PRMB and Qiongdongnan Basins. The activity of neotectonic faults and diapirism related to deep thermal fluid flow provide suitable conditions for vertical migration of hydrocarbons. Suitable fault zone configurations, regional unconformities and permeable sandstone units provide effective migration conduits.

The high commercial thresholds of deepwater exploration demand the discovery must be large enough. Deepwater exploration in the northern SCS must focus on prolific sags for the optimal selection of plays and the identification of large structural traps. For example, in the Baiyun Sag, deepwater exploration will target reservoir identification around the $23.8 \mathrm{Ma}$ shelf-break to delineate effective structures and large sandstone reservoirs near earlier discoveries; in the Liwan Sag, evaluations of the remaining untested large structures forhydrocarbon potential will continue. In the Qiongdongnan Basin, exploration should target at the central channel and expand to lithological traps to test large structures and reefs in the intra-sag highs and uplifts. Furthermore, forthcoming regional surveys and evaluations in the southern parts of the PRMB and Qiongdongnan Basin will identify more deepwater basins and sags and launch a new era in deepwater exploration.

\section{Conclusions}

Deepwater exploration in the SCS has the potential to provide a reliable energy supply, improve basic geological understanding of the region, enhance technological capabilities, develop deepwater industries, and play an important role in safeguarding national sovereignty and territorial integrity.

Current studies of deepwater basins rely mainly on seismic data because of the small number of wells drilled to date. Seismic data demonstrate that the maximum deposition thickness is $8000-10000 \mathrm{~m}$, although present studies are limited to Cenozoic strata. Pre-Cenozoic strata can be 
identified in some areas separated from the overlying $\mathrm{Ce}$ nozoic by a regional angular unconformity, but the physical characteristics, structure and lithology of these units are poorly understood. Even in intensively studied Cenozoic basins, wells have only been drilled to a maximum of about $3000 \mathrm{~m}$ to test the Oligocene reservoir. So, questions associated with basin formation and the evolution of basin tectonics and deposition still need to be resolved.

Exploration and petroleum geology studies in the deepwater basins of the SCS require not only investment from the petroleum industry, but also the complementary support of fundamental scientific studies. Developing an understanding of basic scientific topics such as the formation and evolution of the South China Sea will provide a theoretical basis and framework for petroleum exploration. Seismic and well data acquired during exploration activities will provide abundant first-hand material for basic studies to verify and constrain analyses.

This work was supported by the National Basic Research Program of China (2009CB219400).

1 Zhu W L. Some key geological issues on oil and gas exploration in the northern deepwater area of the South China Sea (in Chinese). Acta Geol Sin, 2009, 83: 1059-1064

2 Gong Z S. The Major Oil and Gas Fields of China Offshore (in Chinese). Beijing: Petroleum Industry Press, 1997. 1-5

3 Taylor B, Hayes D E. Origin and history of the South China Sea basin. In: Hayes D E, ed. The tectonic and geological evolution of southeast Asian seas and islands: Part 2. AGU Geophys Monogr,
1983, 27: 23-56

4 Northrup C J, Royden L H, Burchfiel B C. Motion of the Pacific plate relative to Eurasia and its potential relation to Cenozoic extension along the eastern margin of Eurasia. Geology, 1995, 23: 719722

5 Gong Z S, Li S T, Xie T J, et al. Continental Margin Basin Analysis and Hydrocarbon Accumulation of the Northern South China Sea (in Chinese). Beijing: Science Press, 1997. 63-74

6 Zhu W L, Zhang G C, Gao L. Geological characteristics and exploration objectives of hydrocarbons in the northern continental margin basin of South China Sea (in Chinese). Acta Petrol Sin, 2008, 29: 1-9

7 Zhu W L. Gas geology of northern South China Sea continental margin basins (in Chinese). Beijing: Petroleum Industry Press, 2007. 71-112

8 Mi L J, Yuan Y S, Zhang G C, et al. Characteristics and genesis of geothermal field in deep-water area of the northern South China Sea (in Chinese). Acta Petrol Sin, 2009, 30: 27-32

9 VAN Aarssen B G K, Cox H C, Hoogendoorn P, et al. A cadinene biopolymer in fossil and extant dammar resins as a source for cadinanes and bicadinanes in crude oils from southeast Asia. Geochim Cosmochim Acta, 1990, 54: 3021-3031

10 Li Y C, Deng Y H, Zhang G C, et al. Tertiary marine source rocks in the northern South China Sea (in Chinese). Acta Petrol Sin, 2011, 32: 219-225

11 Zhu W L. Paleolimnology and Source Rock Studies of Cenozoic Hydrocarbon-bearing Offshore Basins in China (in Chinese). Beijing: Geological Publishing House, 2009. 90-94

12 Chen C M, Shi H S, Xu S C, et al. Formation Conditions of Oil and Gas Reservoir in Tertiary in the Eastern Pearl River Mouth Basin (in Chinese). Beijing: Science Press, 2003

13 Pang X, Chen C M, Peng D J, et al. The Pearl River Deep-water Fan System and Petroleum in South China Sea (in Chinese). Beijing: Science Press, 2007

14 Wang Y M, Xu Q, Li D, et al. Late Miocene Red River submarine fan, northwestern South China Sea. Chin Sci Bull, 2011, 56: 14881494

Open Access This article is distributed under the terms of the Creative Commons Attribution License which permits any use, distribution, and reproduction in any medium, provided the original author(s) and source are credited. 